\title{
OPINION
}

\section{Is saying NO to 'accident proneness' throwing the baby out with the bathwater?}

\author{
Peter Wright
}

As a relative newcomer to injury research, I am very much aware that being asked to defend the concept of injury proneness is akin to going 10 rounds in the ring with Mike Tyson. You just can't win! So what is it about proneness that makes the idea so unpalatable? The papers republished in this issue are not easy to dismiss as examples of flawed science (see pages 135 and 144). They provide impressive evidence that some children have increased injury susceptibility. Indeed, there are other more recent examples from the UK of such 'accident repeaters' in both the Oxford Record Linkage Study ${ }^{1}$ and from the 1970 British Birth Cohort Study. ${ }^{2}$

I am going to assume that we can discount type of caregiver, behaviour, or style as an explanation for injury susceptibility. Thus, we are searching for a characteristic of the child per se. However, is the effect due to a 'trait', a quasipersonological characteristic that emerges early in development and which is unchanging or to social background factors? To talk about any stable trait in a child under the age of 10 is debatable, either because of difficulty of measurement and/or the possibility that such traits or behavioural patterns do not achieve stability until the child is older. That said, it is intriguing that the same set of behavioural characteristics associated with frequent injury groups emerge across so many independent studies-'impulsive, aggressive, inattentive, active, etc'. And, as Matheny has commented, there appear to be no studies where the group in question is described as 'more attentive, less active, more cooperative, or less cautious'.

\section{A new candidate for injury proneness}

There is one example of an easily measured, stable characteristic, that has been associated with increased injury risk in adults, ${ }^{3}$ and, more recently, in children ${ }^{4}$ : whether they are right or left handed. The initial findings from adults were based on self retrospective reports about injury occurrence. There is also some support from case studies with evidence of increased injury incidence in left handers, ${ }^{5}$ and from archival studies of cricketers showing an association between handedness and deaths of young service men in wartime. ${ }^{6}$

A case-control study of 6-18 year old children brought to a paediatric emergency department for unintentional injuries found a left handed incidence of $18 \%$ compared with $10.5 \%$ in a non-injured control group. ${ }^{7}$ Among left handers in both the trauma and control groups, some $20 \%$ had been previously hospitalised for injury compared with $12 \%$ of right handers. Virtually identical figures for hospitalisation $(20.6 \%$ left handed and $14 \%$ right handed children) was found in our own study of Scottish adolescents. ${ }^{4}$

Could the increased injury incidence of the left handed children be simply a reporting bias? This seems unlikely when we examine the differences in pattern of injury circumstances (see table). There is evidence of increased risk for left handers in only some locations, such as houses other than their own, or in potentially dangerous environments, such as roads or on farms. The handedness classification used in these studies effectively puts all children who are not right handed into the left handed group; in other words it includes a group who exhibit mixed handedness. Some argue that it is this ambidextrous group that is the more injury prone. ${ }^{9}$ The jury is still out on this issue.

To resolve this question, it would be a relatively simple matter for hospital casualty departments to routinely record handedness in children and thus obtain definitive evidence for any such association. They should, however, use a validated handedness inventory, question the children directly, and not rely on secondary sources, such as parents, for this information.

Of course, it will be argued by advocates of environmental intervention measures that such studies may well reveal a statistically significant difference, but in overall terms the contribution of handedness to total injuries is but a few per cent. A further objection often made to the search for such indicants of accident proneness is that, even if found, because they are stable and inherent characteristics, they are not subject to change and therefore there is nothing that can be done to protect such children.

In the case of left handedness this is simply not the case regardless of which of the two broad explanations for their injury susceptibility is correct. One explanation highlights the problem of living in a right designed world in

Circumstances of injury as a function of handedness

\begin{tabular}{lll}
\hline Place & $\begin{array}{l}\text { Relative risk } \\
(95 \% \text { CI })\end{array}$ & Significance \\
\hline Own house & $0.99(0.68$ to 1.44$)$ & $\mathrm{NS}$ \\
Another house & $1.68(1.02$ to 2.77$)$ & $\mathrm{p}<0.04$ \\
Road & $1.39(1.01$ to 1.91$)$ & $\mathrm{p}<0.04$ \\
Park & $0.66(0.37$ to 1.18$)$ & $\mathrm{NS}$ \\
Farm & $2.64(1.12$ to 6.22$)$ & $\mathrm{p}<0.02$ \\
\hline
\end{tabular}

$\mathrm{CI}=$ confidence interval

Psychology, University of Edinburgh, 7 George Square, Edinburgh EH8 9JZ, Dr Wright.
} 
which tools, equipment, and buildings are all designed for the right handed majority but increase injury risk for the left handed. This certainly makes it incumbent on schools to ensure that the appropriate tools are available for left handed children and that appropriate protective equipment for sport and leisure activities is also provided.

The second explanation is bound up with left handers own self perception as being more clumsy, perhaps as a result of being told so by other people. We found this was true of the Scottish children, as did Graham et al. ${ }^{7}$ This could arise from learning a complex skill such as handwriting, which inevitably appears more untidy in the early years, and gives rise to feelings of inferiority when commented on. Ensuring that teachers are aware of such issues should decrease the likelihood of these children developing poor self esteem.

The importance of skills' analysis

By focusing more on the idea of increased injury susceptibility at particular ages, accident proneness is made more acceptable because the possibility of change is implicit in the course of development. It also encourages a search for explanations of such phases in development, and from these are borne useful intervention measures. Analysis of the skill component involved in road crossing behaviour is a good example. ${ }^{10}$ In one study children were instructed in a real road environment close to their schools to choose 'the safest' crossing sites and routes to a specified destination. Children 5 to 7 years old were very poor at identifying unsafe road crossing sites compared with older children, and their judgments relied exclusively on cars they could see nearby. Blind summits, obscuring obstacles, or complex junctions were not recognized as dangerous and they invariably chose the most direct route, rather than make a safer detour. Substantial improvements were subsequently achieved in the training programme because the requisite skills had been identified. Far from such skills being dependent on matura tional factors, as is often assumed in road safetro research, development was accelerated through. a training procedure that aimed at providin the children with appropriate experience from which to learn for themselves.

So finally, yes, by all means lets press ahea象 with passive measures and legislation, wher appropriate, but in doing so we should nof neglect the search for causes of injury. Statis ${ }^{\infty}$ tical approaches are essentially descriptive $\vec{\rho}$ whereas psychological approaches generat $\overrightarrow{\mathrm{e}_{\mathrm{H}}}$ testable hypotheses with regard to the behao viour or personality of 'repeaters'. Parents (ant children) will continue to believe that some children have more injuries than others. It is our job to demonstrate that such fatalism should be set aside.

1 Eminson C, Jones H, Goldacre M. Repetition of accidents i young children. $\mathcal{F}$ Epidemiol Community Health 1986; 40:

170-3.
2 Bijur P, Golding J, Haslum M. Persistence of occurrence of injury: can injuries of preschool children predict injuries of school-aged children? Pediatrics 1988; 82: 707-12.

3 Coren S. Left-handedness and accident-related injury risk Am $\mathcal{f}$ Public Health 1989; 79: 1040-1.

4 Wright $P$, Williams JM, Currie CE, Beattie TF Lef handedness increases injury risk in adolescent girls Percept Mot Skills 1996; 82: 855-8.

5 MacNiven E. Increased prevalence of left-handedness victims of head trauma. Brain Inj 1994; 8: 457-62.

6 Aggleton JP, Bland AA, Kentridge RW, Neave NJ. Hande $\overrightarrow{5}$ ness and longevity-archival study of cricketers. BMS 1994; 309: $1681-4$.

7 Graham CJ, Dick RI, Rickert VI, Glenn R. Left-handednes? as a risk factor for unintentional injury in children? Pediatrics 1993; 92: 823-6

8 Currie CE, Williams JM, Wright $P$, Beattie TF, Harel $\overline{\bar{F}}$ Incidence and distribution of injury among schoolchit: dren aged 1-15. Injury Prevention 1996; 2: 21 -6.

9 Daniel MT, Yeo RA. Handedness and accident pronenes? Am ₹ Public Health 1991; 81: 1346-7.

10 Ampofo-Boateng K, Thompson JA, Grieve R, Pitcairn To Lee DN, Demetre JD. A developmental and training study of children's ability to find safe routes to cross the road. British fournal of Developmental Psychology 1993; to road. British fournal of Developmental Psychology 1993;
$31-45$.

\title{
'Accident proneness': statistical and practical significance
}

\author{
John D Langley
}

Injury Prevention Research Unit, Department of Preventive and Social Medicine, University of Otago Medical School, Dunedin, New Zealand

Correspondence to: Dr Langley.
The two classics reprinted in this issue are among the most frequently quoted papers to support the notion of accident proneness (see pages 135 and 144). I suspect, however, that many have quoted the papers without having read them critically. To compound the situation, it would appear that there are other quoters who have never read the papers. They, in effect, quote the quoters. Before long the mere repetition becomes all that is necessary and sufficient to establish the findings as fact.
It is not my intention to review each stud确 here as that has been done on many other occasions. Rather, I wish to focus on the practical implications the authors of these two papers, and those of a selection of subsequen similar studies, drew from their findings. This contrasts with what appears to be the focus of many other readers, namely statistical significance.

The necessity for such a focus was brought home to me a few years ago when an associate 